Case report

Perinatology Vol. 30, No. 3, September, 2019 https://doi.org/10.14734/PN.2019.30.3.171

\title{
Repetitive Spontaneous Uterine Rupture in the First Trimester after Laparoscopic Myo- mectomy: A Case Report and Review of Literature
}

\author{
Seungho Kim, MD', \\ Hye Jung Cho, MD', \\ Hyun Soo Park, MD, PhD, MPH ${ }^{1,2}$, \\ Chae Hyeong Lee, MD, $\mathrm{PhD}^{1,2^{\prime}}$ \\ Sang Ho Yoon, MD, PhD ${ }^{1,2}$, \\ Ju-won Roh, MD, PhD ${ }^{1,2}$, \\ Hayan Kwon, MD, MS ${ }^{1,2}$
}

'Department of Obstetrics and Gynecology, Dongguk University Ilsan Hospital, Goyang; ${ }^{2}$ Department of Obstetrics and Gynecology, Dongguk University College of Medicine, Goyang, Korea

Received: 19 December 2018

Revised: 24 January 2019

Accepted: 24 January 2019

Correspondence to

Hayan Kwon, MD, MS

Department of Obstetrics and

Gynecology, Dongguk University

Ilsan Hospital, Dongguk University

College of Medicine, 27 Dongguk-ro,

Ilsandong-gu, Goyang 10326, Korea

Tel: +82-31-961-7366

Fax: +82-31-961-7155

E-mail:whitekwonmd@gmail.com

Copyright@ 2019 by The Korean Society of Perinatology

This is an Open Access article distributed under the terms of the Creative Commons Attribution Non-Commercial License (http://creativecommons.org/ license/by-nc/4.0/), which permits unrestricted non-commercial use, distribution, and reproduction in any medium, provided that the original work is properly cited.
Uterine rupture during pregnancy is one of the most life-threating complications to both mother and fetus. Uterine rupture after myomectomy generally occurs in the third trimester or during labor, therefore, uterine rupture in the first trimester is a very rare complication. Laparoscopic myomectomy scores over laparotomy in several parts. However, the possibility of uterine rupture in the following pregnancies should not be underestimated. We present a case of repetitive spontaneous uterine rupture in the first trimester ( 7 weeks and 10 weeks) and discuss strategies to prevent uterine rupture following laparoscopic myomectomy.

Key Words: Uterine rupture, Uterine myomectomy, Laparoscopic surgery, Pregnancy trimester, first

\section{Introduction}

Uterine rupture in pregnancy is defined as complete separation of the wall and serosa of the pregnant uterus. It is one of the most life-threatening complications leading to massive hemorrhage, shock, and even fetal and maternal mortality. Although it may occur spontaneously without scarred uterus, the most common cause of uterine rupture is the presence of scar tissue including previous myomectomy and cesarean delivery.

The risk of uterine rupture in pregnancy after myomectomy is around $0.75-1 \%$ according to approach methods. ${ }^{1,2}$ Although the incidence is very low, it is associated with fatal complications to both mother and fetus, suggesting that myomectomy in reproductive patients should be carefully assessed and performed. Almost all cases of uterine rupture after myomectomy occurred in the third trimester or labor. ${ }^{3}$ Because uterine rupture in the first trimester is very rare condition, massive bleeding and serious complications could occur by failing to diagnose uterine rupture in early pregnancy with abdominal pain. So, it is important to keep in mind that uterine rupture could happen in women with surgical history of myomectomy. We present a rare case of recurrent uterine rupture in the first trimester after laparoscopic myomectomy, and discuss operative strategies to prevent uterine rupture following pregnancy after laparoscopic myomectomy.

\section{Case}

A 36-year-old primigravida pregnant woman at 10 weeks and 3 days of gestation, was transferred to the emergency department of Dongguk University Ilsan Hospital due to severe abdominal pain and diarrhea with vaginal bleeding. The patient had a history of laparoscopic myomectomy for $5 \mathrm{~cm}$ sized intramural myoma involving the fundus before 3 years. 
Approximately 7 months after the operation (laparoscopic myomectomy), she was pregnant. However, at 7 weeks of gestation, spontaneous uterine rupture occurred around left side of fundus, and was repaired by laparoscopic approach at another institution. After 2 years, she was pregnant and received regular antenatal care before she was transferred to Dongguk University Ilsan Hospital.

Physical examination revealed that blood pressure was 99/49 $\mathrm{mmHg}$ and the heart rate was 105 beats per min. Whole abdomen tenderness and rebound tenderness was observed. Transvaginal ultrasonography was performed and no gestational sac with hyperechoic lesion was observed within the uterine cavity (Fig. 1).

Based on clinical manifestation with surgical history, uterine rupture was suspected. An emergency diagnostic laparoscopy was performed immediately with informed consent. Intraoperative findings revealed about $1,000 \mathrm{~mL}$ blood in the abdominal cavity with active bleeding from the perforated myometrium near the fundus (Fig. 2). Owing to the difficulty of laparoscopic approach to uterine rupture site and adherent mesentery, the operation was converted to laparotomy. During exploration, the anterior wall of uterus near to fundal area was perforated about $3 \mathrm{~cm}$ in diameter and there were protruding conceptive tissues in rupture site (Fig. 3). The protruding conceptive tissues were gently removed, and the myometrium was repaired by doublelayer closure and serosa was repaired finally, resulting in a total

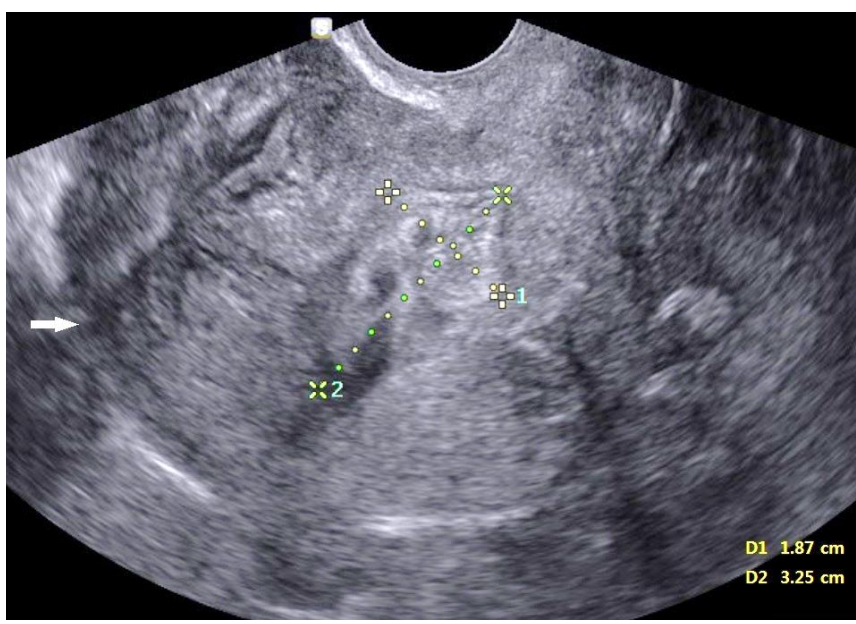

Fig. 1. Ultrasonography image of invisible gestational sac within intrauterine cavity. The arrow showed disconnected myometrial layer and broken myometrium. The heterogeneous lesion measures about $3.3 \times 1.9 \mathrm{~cm}$ in size, presumed ongoing hematoma due to perforated uterus. repair of three layers. Five units of packed red blood cells were transfused, and the postoperative course was uneventful. Histopathological examination was confirmed by the production of conception tissues with endometrium.

\section{Discussion}

As the number of women undergoing myomectomy has increased in recent years following treatment for infertility and increased the average maternal age at childbirth, the number of

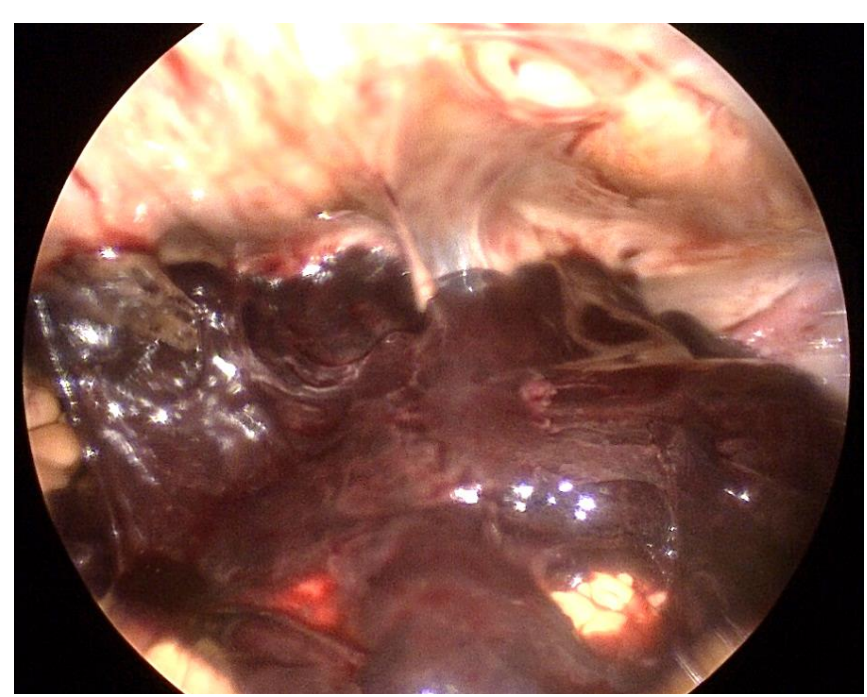

Fig. 2. Massive hemoperitoneum in the pelvic cavity at first sight of diagnostic laparoscopy.

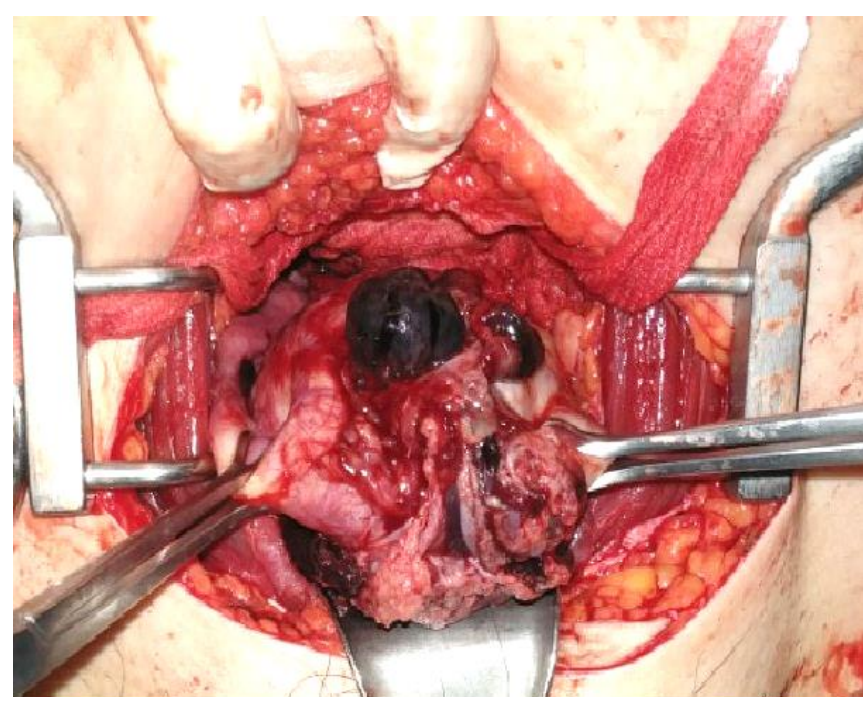

Fig. 3. Operative image of uterine rupture at the fundal site during abdominal exploration. 
pregnant women with a history of myomectomy is growing in the obstetric care unit. As pregnancy after myomectomy may increase the risk of uterine rupture, ${ }^{4}$ the physician should evaluate the risks and complications in the reproductive patient with myoma. ${ }^{5}$

In our patient, spontaneous uterine rupture occurred twice in the first trimester at 7 weeks and 10 weeks of gestational age. It was a very rare condition because uterine rupture typically occurs during active labor or in third trimester. ${ }^{3}$ The potential causes of uterine rupture in early pregnancy in the present case include laparoscopic uterine surgery twice for myomectomy and uterine wall repair surgery for first uterine rupture, and the interval between myomectomy and pregnancy was not enough for complete wound healing .

Uterine rupture after laparoscopic surgery generally occurs due to failure to meticulously close the myometrial bed, poor hemostasis with subsequent hematoma formation or excessive use of monopolar or bipolar electrosurgery, devascularization of the myometrium by thermal damage. ${ }^{6}$ In addition, the opening of the uterine cavity, the extent of local tissue destruction, development of infection, and single-layer sutures are risk factors for uterine rupture. $^{7}$

Several studies suggest operative strategies to reduce uterine rupture in subsequent pregnancies. First, women with myomectomy carry a higher risk of uterine rupture in subsequent pregnancy, even after removal of superficial sub-serosal myomas. ${ }^{2}$ The physician should consider the benefits and complications of myomectomy in a reproductive patient depending on the site and size of myomas. Second, multilayer uterine closure of myometrial bed and avoidance of entry into the endometrial cavity are also recommended. ${ }^{2,6,8}$ Because a multilayer repair can improve the strength of the wound and decrease the risk of postoperative hematoma formation, which can also interfere with optimal tissue healing. ${ }^{9}$ Based on systemic review, there is no significant difference between the incidences of uterine rupture during pregnancy following laparoscopic versus an open myomectomy ( $1.2 \%$ vs. $0.4 \%, P=0.119){ }^{10}$ Therefore, regardless of surgical approach, multilayered closure of the myometrium is recommended. Third, during laparoscopic myomectomy, excessive monopolar or bipolar coagulation for hemostasis should be avoided because it reduces vascularization and interferes with wound remodeling. Laparoscopic electrolysis is one of mini- mal invasive surgery that blood supply of uterine myoma was blocked by electrocauterization and the procedure results in shrunken myoma instead of complete excision. ${ }^{11}$ However, in spite of the benefits, devascularization itself is one of the predisposing factors for healing because of poor vascularity of uterine muscles and destroying blood supply is a risk factor for wound healing even unscarred uterus. ${ }^{12}$ The new technology for myoma, targeted volumetric thermal ablation such as radiofrequency fibroid ablation, magnetic resonance-guided focused ultrasonography surgery or high intensity focused ultrasonography are related with coagulative necrosis on the uterus. These changes may affect implantation, placentation, and uterine contractility during labor, thus increasing the risk of uterine rupture. ${ }^{13}$ As we mentioned, the incidence of uterine rupture is variable ranges at literatures and $0.03-0.08 \%$ of uterine rupture was revealed in women with unscarred uterus. ${ }^{10,14}$ It commonly occurs for women with past history of uterine surgery without a scar. ${ }^{15}$ Therefore, minimal coagulation and avoiding poor vascularity may contribute to preserve the integrity of uterine myometrium.

Although the incidence of unscarred uterine rupture is not frequent, uterine rupture in any pregnancy after laparoscopic procedures is increasing. In addition, adequate interval between myomectomy and pregnancy reduces uterine rupture. Although there is no guideline about safe interval, a few studies recommend 12 to 24 months to decrease the complications of pregnancy after myomectomy. ${ }^{16-18}$ It is important to balance between uterine wound healing and reproductive outcomes. A study of uterine wound healing using magnetic resonance imaging reported that the uterine healing process was complete at 12 weeks after abdominal myomectomy in the absence of hematoma or edema formation in the myometrium. ${ }^{17}$ Another study with 471 patients, the average interval in the live birth group was much shorter than in the non-live birth group (15.0 \pm 8.4 months vs. $18.9 \pm 9.3$ months, $P=0.005) .{ }^{19}$ This indicates that a longer interval may not get better reproductive outcomes, but adequate interval should be considered.

In conclusion, as the wide use of laparoscopic procedures like myomectomy and electromyolysis with remarkable benefits, careful selection of patients and accurate surgical procedure by a surgeon proficient in laparoscopy is essential. Also, it should be accompanied with informed consent about complications because 
the uterine rupture is a fatal condition and the consequence is irreversible. Therefore, when considering laparoscopic procedures for myoma in reproductive-age women, strict selection criteria for surgical indications and intraoperative strategies to reduce uterine rupture in subsequent pregnancies are highly recommended.

\section{Conflict of Interest}

No potential conflict of interest relevant to this article was reported.

\section{References}

1) Claeys J, Hellendoorn I, Hamerlynck T, Bosteels J, Weyers S. The risk of uterine rupture after myomectomy: a systematic review of the literature and meta-analysis. Gynecol Surg 2014;11:197-206.

2) Dubuisson JB, Fauconnier A, Deffarges JV, Norgaard C, Kreiker G, Chapron C. Pregnancy outcome and deliveries following laparoscopic myomectomy. Hum Reprod 2000;15:869-73.

3) Kim HS, Oh SY, Choi SJ, Park HS, Cho GJ, Chung JH, et al. Uterine rupture in pregnancies following myomectomy: a multicenter case series. Obstet Gynecol Sci 2016;59:454-62.

4) Milazzo GN, Catalano A, Badia V, Mallozzi M, Caserta D. Myoma and myomectomy: poor evidence concern in pregnancy. J Obstet Gynaecol Res 2017:43:1789-1804.

5) Kim MS, Uhm YK, Kim JY, Jee BC, Kim YB. Obstetric outcomes after uterine myomectomy: laparoscopic versus laparotomic approach. Obstet Gynecol Sci 2013;56:375-81.

6) Vimercati A, Del Vecchio V, Chincoli A, Malvasi A, Cicinelli E. Uterine rupture after laparoscopic myomectomy in two cases: real complication or malpractice? Case Rep Obstet Gynecol 2017;2017:1404815.

7) Parker WH, Einarsson J, Istre O, Dubuisson JB. Risk factors for uterine rupture after laparoscopic myomectomy. J Minim Invasive Gynecol 2010;17:551-4.

8) Sutton C, Standen P, Acton J, Griffin C. Spontaneous uterine rupture in a preterm pregnancy following myomectomy. Case Rep Obstet Gynecol 2016;2016:6195621.

9) Flyckt RL, Falcone T. Uterine rupture after laparoscopic myomectomy. J Minim Invasive Gynecol 2015;6:921-2.

10) Kieser KE, Baskett TF. A 10-year population-based study of uterine rupture. Obstet Gynecol 2002;100:749-53.

11) Abbas AM, Sheha AM, Ali MK, Ali SS, Salem NZ, Talaat E, et al. Secondtrimester spontaneous uterine rupture after laparoscopic electromyolysis in nulligravida: a case report. Middle East Fertility Society Journal 2017; 22:73-6.

12) Pelosi MA 3rd, Pelosi MA. Spontaneous uterine rupture at thirty-three weeks subsequent to previous superficial laparoscopic myomectomy Am J Obstet Gynecol 1997;177:1547-9.

13) Keltz J, Levie M, Chudnoff S. Pregnancy outcomes after direct uterine myoma thermal ablation: review of the literature. J Minim Invasive Gynecol 2017;24:538-45.

14) Leung AS, Leung EK, Paul RH. Uterine rupture after previous cesarean delivery: maternal and fetal consequences. Am J Obstet Gynecol 1993; 169:945-50.

15) Veena $P$, Habeebullah S, Chaturvedula L. A review of 93 cases of ruptured uterus over a period of 2 years in a tertiary care hospital in South India. J Obstet Gynaecol 2012;32:260-3.

16) Bujold E, Mehta SH, Bujold C, Gauthier RJ. Interdelivery interval and ut erine rupture. Am J Obstet Gynecol 2002;187:1199-202.

17) Tsuji S, Takahashi K, Imaoka I, Sugimura K, Miyazaki K, Noda Y. MRI evaluation of the uterine structure after myomectomy. Gynecol Obstet Invest 2006;61:106-10.

18) Koo YJ, Lee JK, Lee YK, Kwak DW, Lee IH, Lim KT, et al. Pregnancy outcomes and risk factors for uterine rupture after laparoscopic myomec tomy: a single-center experience and literature review. J Minim Invasive Gynecol 2015;22:1022-8.

19) Zhang Y, Hua KQ. Patients' age, myoma size, myoma location, and interval between myomectomy and pregnancy may influence the pregnancy rate and live birth rate after myomectomy. J laparoendosc Adv Surg Tech A 2014;24:95-9. 